\title{
Whooping cough diagnosis: a clinical evaluation of complementing culture and immunofluorescence with enzyme-linked immunosorbent assay of pertussis immunoglobulin A in nasopharyngeal secretions
}

\author{
P. B. CAMPBELL, P. L. MASTERS and ELIZABETH ROHWEDDER*
}

\begin{abstract}
Department of Microbiology, Princess Margaret Hospital for Children, 2 Roberts Road, Subiaco, Western Australia, and *Planning and Research Department, Health Department of Western Australia, Perth, Western Australia, Australia
\end{abstract}

\begin{abstract}
Summary. Pernasal aspirate (PNA) was obtained from 543 children during a 6-month period when whooping cough was prevalent. Three tests for diagnosing pertussis were performed on the PNA: (a) examination of direct smears by immunofluorescence (IF) for Bordetella pertussis; (b) culture; and (c) estimation of $B$. pertussis-specific immunoglobulin-A antibody (P-IgA) by an enzyme-linked immunosorbent assay (ELISA). On clinical review, 395 children were assessed to have had pertussis ( $P$ children) and 148 children not to have had pertussis (non-P children). The non-P children comprised 66 admitted to hospital for acute respiratory infections and 82 outpatients suspected of having pertussis. Analysis of the results of the tests on the PNAs of the non-P children helped to assess the P-IgA test. The analysis showed that artificial immunisation against pertussis did not affect the antibody results, but that non-specific positive results occur requiring the labelling of many P-IgA results as "doubtful". Among the $395 \mathrm{P}$ children, $36 \%$ yielded positive cultures and more than half of these also had positive IF tests. The ELISA for P-IgA was positive in $24 \%$ of all the $\mathrm{P}$ children, equivalent to nearly $40 \%$ of the culture-negative $\mathrm{P}$ children. For the 148 non-P children, IF and culture-negative by definition, the P-IgA test was positive in $9 \%$. The antibody test result was doubtful in $28 \%$ of the $\mathrm{P}$ children and in $40 \%$ of the non-P children. Estimation of P-IgA antibodies in PNA is a useful and economic complement to culture and IF in the diagnosis of pertussis. The occurrence of non-specific positive results makes evaluation of the clinical features of the child essential to the interpretation of the test.
\end{abstract}

\section{Introduction}

In affluent countries, whooping cough is a rare cause of death. For this reason the frequency with which the infection causes prolonged family distress is liable to be discounted. Johnston et al. (1985) recently wrote: "Parents suffered especially from fears for the life and health of their child and from loss of sleep". In the absence of an effective way of shortening the course of the illness (Broomhall and Herxheimer, 1984), prevention continues to be the only practical option.

Received 2 Sep. 1987; revised version accepted 25 April 1988. *Correspondence should be sent to P. B. Campbell, Department of Microbiology, Princess Margaret Hospital for Children, GPO Box D184, Perth, Western Australia 6001.
The evaluation of immunisation programmes is crucial, therefore, but has been hampered by difficulties in diagnosis. The whoop is often absent in young babies and older children, and culture is often negative on clinical presentation, particularly in immunised children (Baraff et al., 1978; Linneman, 1979). Conventional serological tests have been disappointing (Robinson et al., 1981). The recently developed enzyme-linked immunosorbent assays (ELISAs) for pertussis antibodies in the three main classes of immunoglobulin have so far been applied mainly to serum, and may require the collection of paired sera for reliable diagnosis (Granstrom et al., 1982; Mertsola et al., 1983). Differences in technique and problems of standardisation have made comparisons between ELISA 
methods difficult, as explained by Onorato and Wassilak (1987) in a review of the laboratory diagnosis of pertussis. They state: "At this time no ELISA technique for the diagnosis of pertussis is approved for routine use in the United States". The use of an ELISA for pertussis-specific immunoglobulin $\mathrm{A}(\mathrm{P}-\mathrm{IgA})$ in pernasal aspirates reported from Canada (Goodman et al., 1981) seems a logical way to improve the diagnosis of a non-invasive mucosal infection. The authors presented evidence that their test is bacteriologically specific, but did not explore the possibility that false positive results may be produced in viral respiratory infections or assess the sensitivity of the test in detecting culturenegative pertussis.

We used an expected larger seasonal rise of pertussis during 1984-85 to attempt a clinical evaluation of the reliability of the test in diagnosing culture-negative pertussis and in distinguishing pertussis from other acute respiratory infections.

\section{Patients and methods}

\section{Patients}

Two groups were recruited: (i) children with suspected pertussis attending the hospital or attending private practitioners and sent to the Microbiology Department for diagnostic tests; and (ii) children admitted to hospital with respiratory infections for whom tests for virological diagnosis were requested. For the purpose of this study we reviewed all patients in these two groups presenting during the 6-month period from October 1984 to March 1985 if pernasal aspirates were obtained and if the date of birth and duration of cough were available.

\section{Specimens}

Pernasal aspirates (PNAs) were obtained by suction into a mucus trap consisting of a disposable centrifuge tube with a screw cap and two outlet tubes. One of the tubes was connected to on-line suction and the other tube was passed through the nostril to the nasopharyngeal space. The secretion was sucked into the centrifuge tube and diluted with an equal volume of phosphate-buffered saline, $\mathrm{pH} 7 \cdot 3$ (PBS). In cases where there was very little secretion present the tube was rinsed out with a little PBS. If the aspirate was very viscous, a few drops of dithiothreitol (Sputalysin; Behring Diagnostics, USA) were added before the specimen was vortex mixed and then centrifuged. The supernate was stored frozen until tested.

\section{Clinical data}

These were obtained from the laboratory request form, a form filled in by a parent, the hospital medical records and telephone conversations with mothers at or after the time of reporting the laboratory results. Data requested included the child's clinical progress and the number of diphtheria-pertussis-tetanus (DPT) injections received, based on the immunisation card if available. The ages and immunisation status of any siblings and the dates of onset and clinical correlates of recent coughs in other family members were also recorded.

A clinical diagnosis of pertussis was considered if the cough lasted at least 2 weeks, there was a gradual development of a paroxysmal quality to the cough, and the child was well between coughing spasms. If the latter were followed by vomiting or whooping at some stage, unmodified pertussis was diagnosed. In the absence of vomiting or whooping, other evidence for or against a modified attack of pertussis was sought and taken into account:

In favour-in contact with a family member or acquaintance with classical pertussis;

Against - clinical features not usually associated with pertussis, such as high fever, tachypnoea, wheezing, sore throat;

Laboratory results - a positive culture for Bordetella pertussis was accepted as indicating pertussis, but the result of the antibody test was not used to confirm or exclude the diagnosis.

\section{ELISA}

Antigen was prepared from a sonicate of $B$. pertussis, (Princess Margaret Hospital strains 85/75 and 85/76, both containing serofactors $1,2,3$ ) according to the method of Goodman et al. (1981). The optimal dilution of antigen was determined by checkerboard titration. Dilutions were made up freshly for each batch of tests with $0 \cdot 1 \mathrm{M}$ carbonate buffer $\mathrm{pH} 9 \cdot 6$.

Conjugate was prepared from sheep anti-human IgA antibodies provided by Dr G. A. Stewart, Senior Research Officer in the Clinical Immunology Unit of the Princess Margaret Children's Medical Research Foundation, Perth, Western Australia. Antibodies had been raised against a purified human $\operatorname{IgA}$ myeloma protein and were immunopurified before being conjugated to alkaline phosphatase according to the method of Voller et al. (1980). The specificity of the conjugate in ELISA was established with microtitration plates coated with purified IgA, IgG and IgG $\left(\mathrm{Fab}^{1}\right)_{2}$. A dilution of conjugate of 1 in 200 was found by checkerboard titration to be optimal for the test. The diluent was PBS containing Tween 20 (PBS-T) 0.05\%.

The test procedure was an indirect ELISA as described by Voller et al. (1978). Wells of the microtitration plate (Nunclon; Roskilde, Denmark) were coated with $200 \mu 1$ of the optimal dilution of antigen. The plate was kept at $4^{\circ} \mathrm{C}$ for $24 \mathrm{~h}$ and then washed three times with PBS-T; $100 \mu$ of supernate from each PNA was added to a test well. Three reagent blanks in which PBS-T was added to a well in place of a test sample were included with each batch of tests. The plate was held at room temperature 
(RT) for $1.5 \mathrm{~h}$. The washing procedure was again performed (three washes with PBS-T) and $100 \mu \mathrm{l}$ of conjugate was added to each well. After $1.5 \mathrm{~h}$ at RT the plate was washed three times with PBS-T and $100 \mu$ of $p$-nitrophenyl phosphate solution (Sigma) was added as substrate to each well. The plate was held at RT for another $1.5 \mathrm{~h}$ and the optical density at $405 \mathrm{~nm}\left(\mathrm{OD}_{405}\right)$ of each well was read with a microELISA minireader (Dynatech; MR 590). The net OD readings were obtained by subtracting the mean $\mathrm{OD}$ of the reagent blanks from the OD of each test well. A positive control consisting of pooled PNAs yielding high readings from children with pertussis was used in each batch.

\section{Indirect immunofluorescence}

Smears made from the centrifuged deposits of the PNAs were air-dried and fixed in cold acetone. The $B$. pertussis antiserum used in the test was produced in rabbits according to the method of Lautrop and Lacey (1960) and used at a ten-fold dilution in PBS. After a drop of antiserum had been added to each smear, the slides were incubated in a moist chamber at $37^{\circ} \mathrm{C}$ for $30 \mathrm{~min}$. The slides were then immersed in three rinses of PBS, each lasting $10 \mathrm{~min}$, given a final rinse in water and allowed to dry. A drop of antiserum containing fluorescein-labelled antibody to rabbit serum globulin (Behring) was added to each smear, and the slides were again incubated in a moist chamber at $37^{\circ} \mathrm{C}$ for $30 \mathrm{~min}$. They were then given three rinses of PBS, each lasting $5 \mathrm{~min}$, rinsed briefly in water and allowed to dry. Smears were examined under a Leitz Ortholux microscope with incident light fluorescence for the characteristic coccobacillary morphology of $B$. pertussis.

\section{Culture}

Before dilution and centrifugation, loopfuls of each specimen were inoculated on to two Charcoal Agar plates (Oxoid CM119 with horse blood $10 \% \mathrm{v} / \mathrm{v}$ ), one containing cephalexin $40 \mu \mathrm{g} / \mathrm{ml}$, and the other without antibiotics (Sutcliffe and Abbott, 1972). The plates were incubated at $36.5^{\circ} \mathrm{C}$ in a humidified $\mathrm{CO}_{2}$ incubator and examined daily for 5 days before being discarded.

\section{Results}

On the basis of clinical review, 395 of the 543 children tested were assessed to have had pertussis ( $P$ children). As no asymptomatic carriers of $B$. pertussis were detected, the children tested were divided into three main groups: (1) 148 children without pertussis (non-P children); (2) 144 children with culture-positive pertussis; and (3) 251 children with culture-negative pertussis.

\section{ELISA on PNAs of non-P children}

The non-P children included some who yielded high OD readings by ELISA, making relevant any evidence regarding microbiological diagnosis. The PNAs of 47 children were cultured for respiratory viruses, and 22 cultures were positive, including 11 for respiratory syncytial virus. Four other patients had serological evidence of Mycoplasma pneumoniae infection. The PNAs of the other 97 children were not cultured for viruses. The mean duration of symptoms was 12.6 days for the 82 outpatients and 5.4 days for the 66 inpatients.

Table I shows that subdivision of the non-P children according to sex, number of DPTs received, age group or admission to hospital leads to little variation in the geometric mean of the net $O D$ readings in the P-IgA tests. Therefore, we used the results on the whole group of non-P children for comparison with those on the culture-negative $P$ children.

\section{ELISA on PNAs of P children}

The culture-positive $P$ children yielded a geometric mean for their net OD readings of $0 \cdot 165$, close to the geometric mean of $0 \cdot 154$ obtained in the tests on the non-P children (table I). In table II, the ELISA results on the culture-negative $P$ children are compared with those on the non-P children. For the children with a duration of cough at sampling of $\leq 2$ weeks and 2-4 weeks, the differences between the geometric means are highly significant ( $\leq 2$ weeks: $t=5 \cdot 6, d f=183, p<0.01$; 2-4 weeks: $t=2.96, d f=131, p<0.01)$. For the children with a duration of cough exceeding 4 weeks the difference between the geometric means did not achieve statistical significance $(t=1 \cdot 71$, $\mathrm{df}=79, \mathrm{p}=0 \cdot 15$ ), but this may be due to the small number of non-P children in that category, one of which was an asthmatic with a net OD reading of 0.67 .

In fig. 1 the distributions of net OD readings from the three groups of children are shown as lines joining points representing the proportion of children in each group with readings falling within each of the net OD intervals on a logarithmic scale. The lines derived from the 148 non-P children and the 144 culture-positive $P$ children almost coincide and form symmetrical bell-shaped curves confirming that a logarithmic scale is appropriate. We have assumed that the results of the ELISA on PNAs from these groups reflect the presence of antibodies not specific to $B$. pertussis antigens (non-P $\operatorname{IgA}$ ). In contrast, the curve derived from tests on the PNAs 
Table I. ELISA for $B$. pertussis-specific IgA on pernasal aspirates of children without pertussis related to number of DPT injections received, age, admission to hospital and sex

\begin{tabular}{|c|c|c|c|c|c|c|c|c|c|}
\hline \multirow[b]{2}{*}{ Comparative criteria } & \multicolumn{3}{|c|}{ Girls } & \multicolumn{3}{|c|}{ Boys } & \multicolumn{3}{|c|}{ Totals } \\
\hline & Number & $\begin{array}{l}\text { Geometric } \\
\text { mean of net } \\
\text { OD }\end{array}$ & SD & Number & $\begin{array}{l}\text { Geometric } \\
\text { mean of net } \\
\text { OD }\end{array}$ & SD & Number & $\begin{array}{l}\text { Geometric } \\
\text { mean of net } \\
\text { OD }\end{array}$ & SD \\
\hline \multicolumn{10}{|l|}{$\begin{array}{l}\text { Number of } \\
\text { DPTs received }\end{array}$} \\
\hline 0 & 18 & $0 \cdot 140$ & $0 \cdot 130$ & 14 & 0.197 & 0.264 & 32 & $0 \cdot 163$ & $0 \cdot 170$ \\
\hline 1 or 2 & 17 & $0 \cdot 176$ & $0 \cdot 186$ & 12 & $0 \cdot 104$ & 0.092 & 29 & $0 \cdot 141$ & $0 \cdot 160$ \\
\hline 3 or 4 & 25 & 0.147 & 0.108 & 20 & 0.179 & 0.220 & 45 & $0 \cdot 161$ & $0 \cdot 170$ \\
\hline Not ascertained & 19 & $0 \cdot 182$ & $0 \cdot 165$ & 23 & 0.133 & $0 \cdot 147$ & 42 & $0 \cdot 154$ & $0 \cdot 156$ \\
\hline \multicolumn{10}{|l|}{ Age group } \\
\hline$<1$ year & 42 & $0 \cdot 154$ & $0 \cdot 156$ & 39 & $0 \cdot 153$ & 0.204 & 81 & $0 \cdot 153$ & $0 \cdot 179$ \\
\hline$\geq 1$ year & 37 & $0 \cdot 165$ & 0.136 & 30 & 0.148 & $0 \cdot 187$ & 67 & $0 \cdot 157$ & $0 \cdot 160$ \\
\hline \multicolumn{10}{|l|}{ Admission to hospital } \\
\hline Yes & 26 & $0 \cdot 135$ & $0 \cdot 142$ & 40 & $0 \cdot 156$ & 0.236 & 66 & $0 \cdot 147$ & 0.204 \\
\hline No & 53 & $0 \cdot 173$ & 0.149 & 29 & 0.143 & 0.116 & 82 & $0 \cdot 162$ & 0.138 \\
\hline Totals & 79 & $0 \cdot 159$ & $0 \cdot 146$ & 69 & $0 \cdot 151$ & $0 \cdot 196$ & 148 & $0 \cdot 154$ & $0 \cdot 170$ \\
\hline
\end{tabular}

$\mathrm{SD}=$ standard deviation

Table II. ELISA for B. pertussis-specific IgA on PNAs from children with culture-negative pertussis and children without pertussis compared in relation to duration of cough at sampling

\begin{tabular}{l|cccccc}
\hline & \multicolumn{2}{|c}{ Culture-negative pertussis } & & \multicolumn{2}{c}{ Not pertussis } \\
\cline { 2 - 3 } \cline { 5 - 6 } $\begin{array}{c}\text { Duration } \\
\text { of cough } \\
\text { (weeks) }\end{array}$ & $\begin{array}{c}\text { Number of } \\
\text { children }\end{array}$ & $\begin{array}{c}\text { Geometric mean of } \\
\text { net OD }\end{array}$ & & $\begin{array}{c}\text { Number of } \\
\text { children }\end{array}$ & $\begin{array}{c}\text { Geometric mean of } \\
\text { net OD }\end{array}$ & p value \\
\hline$\leq 2$ & 78 & 0.278 & & 107 & 0.144 & $<0.01$ \\
$2-4$ & 103 & 0.267 & & 30 & 0.166 & $<0.01$ \\
$>4$ & 70 & 0.374 & & 11 & 0.266 & 0.15 \\
Total & 251 & 0.297 & & 148 & 0.154 & ND \\
\hline
\end{tabular}

$\mathrm{ND}=$ not determined

of children with culture-negative pertussis peaks at a higher OD reading and is asymmetrical owing to a tail in the lower part of the OD range. We have therefore assumed that the OD readings derived from the children in this group have a non-specific, as well as a specific, component, accounting for some of the overlap with the curves derived from the other two groups. The extent of the overlap is such that on conventional statistical grounds most of the test results would have to be considered doubtful.

We selected the OD range $0 \cdot 16-0 \cdot 40$ (inclusive) as the range for which the diagnosis of pertussis in culture-negative children was in doubt, as indicated in fig. 1. The lower limit of the doubtful range was selected on the assumption that readings below the peak for the ELISA readings on the non-P children were due to the non-specific component and therefore negative. The upper limit of the doubtful range was selected in the knowledge that for most of the non-P children whose PNAs yielded high OD readings, the diagnosis of pertussis was readily excluded on clinical grounds at follow-up. There were 14 non-P children whose PNAs yielded ODs $>0 \cdot 40$. Six of them did not have paroxysmal coughs at any time and the other eight did not have paroxysmal coughs at the time of follow-up. The duration of cough at sampling exceeded 2 weeks in only one of the 14 .

\section{Serial tests}

More than one PNA was collected from 11 children; the details are given in table III. Cases 1-8 


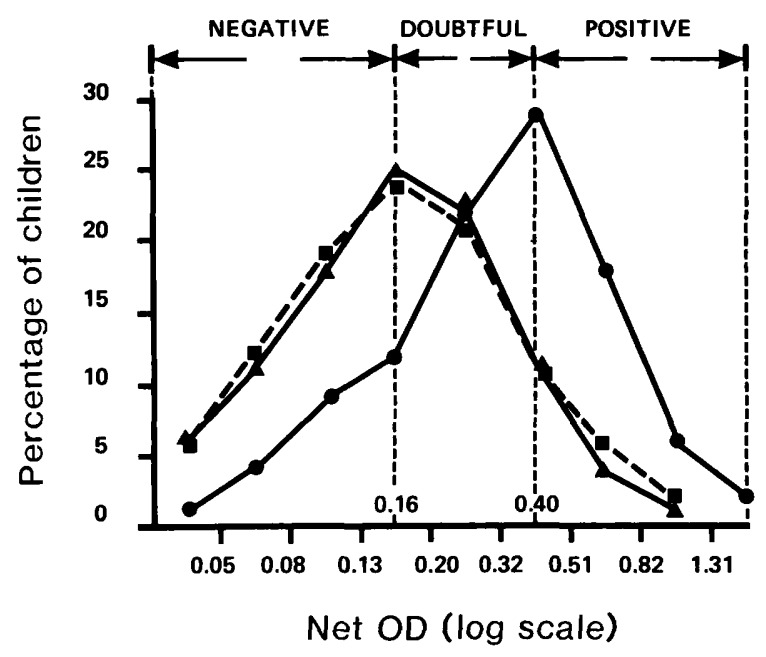

Fig. 1. ELISA results for B. pertussis-specific IgA in PNAs: distribution of net OD readings related to clinical category and culture result. Not pertussis, - - ; pertussis, culturepositive, $---\square---;$ pertussis, culture-negative, $--\bullet-$

were culture-positive on admission to hospital and further PNAs were collected to determine whether they had become culture-negative. For each of these children the net OD obtained with the last PNA was at least double that with the first PNA, and for four of them the net OD obtained with the last PNA was positive $(>0 \cdot 40)$. Case 9 had classical whooping cough and had been breast-fed until a few days before onset. His PNA yielded a positive IF test, but a positive culture could not be confirmed because the culture medium was overgrown with a Proteus sp. His second PNA was taken when he was readmitted for another respiratory infection.
Case 10 was first tested 6 weeks after onset when his antibody test was positive. A repeat, 2 weeks later, gave a lower reading in the antibody test. Case 11 was one of twins, both of whom were admitted to hospital on account of rhinorrhoea, cough and tachypnoea. He had a paroxysmal cough with a slight wheeze, but not with fever, suggesting the diagnosis of pertussis. His twin sister had a fever and her cough was not paroxysmal. Both babies were given a final diagnosis of acute bronchiolitis, and respiratory syncytial virus (RSV) was grown from PNAs obtained from both babies on admission. The net OD readings of the P-IgA tests on the boy were 0.20 (negative) on the fifth day and 0.94 (positive) on the sixth day of illness, while the net OD of the girl's test was 0.36 (doubtful) on admission, 8 days after onset.

\section{Children with clinical pertussis}

Fig. 2 and table IV relate the results of the three tests performed on pernasal aspirates-immunofluorescence on direct films (IF), culture, and ELISA of $\mathrm{P}-\operatorname{IgA}$ - to the duration of the cough at the time of collecting the PNAs. The contribution of each test to diagnosis varies according to the duration of the cough.

Table IV shows that overall IF was positive in $21 \%$ and culture was positive in $36 \%$ of children. All the PNAs positive with IF were culture-positive, except for one in which the culture plates were overgrown with Proteus, and for this reason the percentages of children positive by IF in table IV are bracketed. The remaining $64 \%$ of children who were culture-negative comprised $24 \%$ with positive

Table III. Serial test results

\begin{tabular}{|c|c|c|c|c|c|c|c|c|c|c|c|c|c|c|}
\hline \multirow[b]{2}{*}{$\begin{array}{c}\text { Case } \\
\text { no }\end{array}$} & \multirow[b]{2}{*}{$\begin{array}{c}\text { Age at } \\
\text { onset }\end{array}$} & \multirow{2}{*}{$\begin{array}{l}\text { Number } \\
\text { of DPT } \\
\text { injections }\end{array}$} & \multicolumn{4}{|c|}{ First test results } & \multicolumn{4}{|c|}{ Second test results } & \multicolumn{4}{|c|}{ Third test results } \\
\hline & & & $\begin{array}{c}\text { Duration } \\
\text { (weeks) }\end{array}$ & IF & $\mathrm{C}$ & $\mathrm{Ab}$ & $\begin{array}{c}\text { Duration } \\
\text { (weeks) }\end{array}$ & IF & $\mathrm{C}$ & $\mathrm{Ab}$ & $\begin{array}{c}\text { Duration } \\
\text { (weeks) }\end{array}$ & IF & $\mathrm{C}$ & $\mathrm{Ab}$ \\
\hline 1 & 1 month & 0 & $0 \cdot 3$ & + & + & $0 \cdot 11$ & $1 \cdot 3$ & - & - & $0 \cdot 48$ & $\ldots$ & $\ldots$ & $\ldots$ & $\ldots$ \\
\hline 2 & 3 months & 0 & $0 \cdot 9$ & - & + & $0 \cdot 13$ & $1 \cdot 4$ & - & - & $0 \cdot 50$ & $\ldots$ & $\ldots$ & $\ldots$ & $\ldots$ \\
\hline 3 & 6 years & 3 & $1 \cdot 1$ & + & + & $0 \cdot 10$ & $5 \cdot 4$ & - & - & 0.38 & $\ldots$ & $\ldots$ & $\ldots$ & $\ldots$ \\
\hline 4 & 1 year & 0 & $1 \cdot 1$ & - & + & 0.07 & $2 \cdot 0$ & - & + & 0.07 & $6 \cdot 0$ & - & - & $0 \cdot 14$ \\
\hline 5 & 3 months & 1 & $2 \cdot 6$ & + & + & 0.05 & $4 \cdot 3$ & - & - & 0.38 & $\ldots$ & $\ldots$ & $\ldots$ & $\ldots$ \\
\hline 6 & 1 month & 0 & $3 \cdot 5$ & - & + & 0.04 & $6 \cdot 0$ & - & + & 0.08 & $9 \cdot 0$ & - & - & 0.25 \\
\hline 7 & 2 months & 0 & $5 \cdot 0$ & + & + & $0 \cdot 11$ & $6 \cdot 0$ & - & + & $0 \cdot 26$ & 13.0 & - & - & 0.56 \\
\hline 8 & 1 year & ND & $11 \cdot 4$ & - & + & $0 \cdot 14$ & $12 \cdot 4$ & - & + & 0.06 & $17 \cdot 1$ & - & - & 0.49 \\
\hline 9 & 2 months & 0 & 0.6 & + & ND & 0.72 & $26 \cdot 0$ & - & - & 0.05 & $\ldots$ & $\ldots$ & $\ldots$ & .. \\
\hline 10 & 4 years & 3 & 6.0 & - & - & 0.53 & $8 \cdot 0$ & - & - & 0.43 & $\ldots$ & $\ldots$ & $\ldots$ & $\ldots$ \\
\hline 11 & 2 months & 1 & 0.7 & - & - & 0.20 & 0.9 & - & - & 0.94 & $\ldots$ & $\ldots$ & $\ldots$ & $\ldots$ \\
\hline
\end{tabular}

$\mathrm{IF}=$ immunofluorescence test on direct film; $\mathrm{C}=$ culture; $\mathrm{Ab}=$ antibody test (net $\mathrm{OD}$ reading) $\mathrm{ND}=$ not determined 


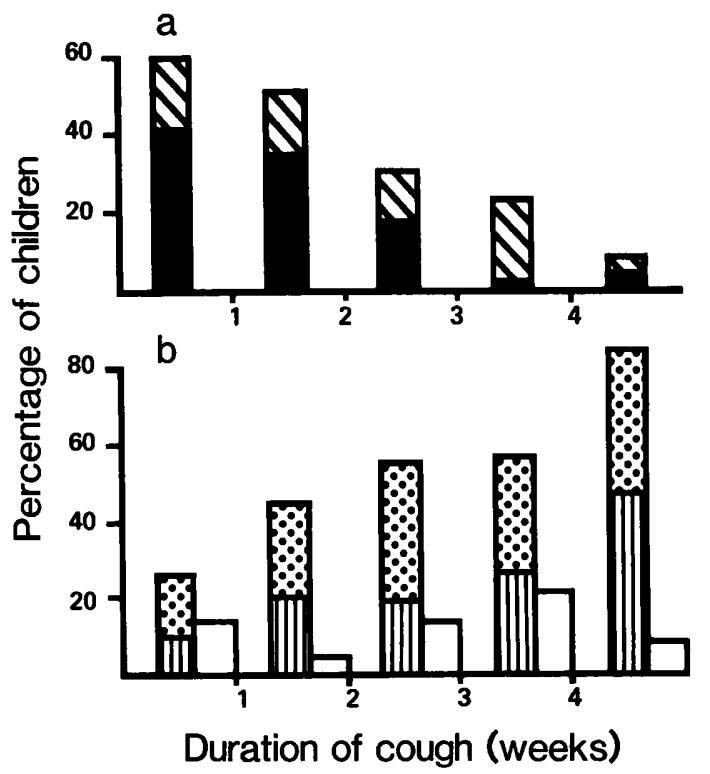

Fig. 2. Children with clinical pertussis: tests on pernasal aspirates correlated with duration of cough at testing. (a) Culture and immunoflourescence (IF): positive culture and IF, $\square$; positive culture only, $\mathbf{N}$.

(b) Antibody tests on culture-negative PNAs: antibody-positive, III ; antibody-doubtful, 图; antibody-negative, $\square$.

antibody tests, $28 \%$ with doubtful antibody tests (OD readings of $0 \cdot 16-0.40$ ) and $12 \%$ with negative antibody tests. The PNA was positive by both culture and antibody tests in $4 \%$; this was most frequent for children in the third week of the cough. All three tests were positive in $2.5 \%$; this was most frequent in the second week.

The order of the test results in table IV is believed to reflect the sequence in time for many children: IF and culture-positive first, then culture-positive only, then negative in both culture and antibody test, then antibody-doubtful, and, finally, antibodypositive. Examples of parts of this sequence are documented in table III. Other children yielded antibody-doubtful or occasionally antibody-posi- tive results while still culture-positive, as indicated earlier.

\section{Discussion}

The results of this study show that the estimation of pertussis-specific $\operatorname{IgA}(\mathrm{P}-\operatorname{IgA})$ antibodies in pernasal aspirates is a useful complement to culture. The convenience of using the same sample for the three diagnostic tests and for virological diagnosis merits emphasis. Moreover, pernasal aspirates are less subject than pernasal swabs to deterioration by drying during transport. The percentage of children yielding positive antibody tests exceeded the percentage yielding positive cultures when the cough had lasted 3 weeks or more (fig. 2) and in the group of children aged 8 years and over.

The data from table 1 support the finding of Goodman et al. (1981) that artificial immunisation does not affect the results of the P-IgA test, and our analysis showed that age, sex and admission to hospital also do not affect these results. Less welcome is the finding that the PNAs of the children without clinical pertussis give an appreciable and variable OD reading in the P-IgA test (table I and fig. 1), sufficient to produce a considerable "grey area" in the interpretation of the antibody test results.

A possible reason for this problem is non-specific binding of secretory $\operatorname{IgA}$ by the whole-cell $B$. pertussis antigen used, a possibility suggested by Onorato and Wassilak (1987). This is suggested by the finding that RSV infection may be associated with a rise in the reading obtained in the antibody test (Case 11, table III). A rise in neutralising IgA antibody to RSV in nasopharyngeal secretion early in this infection has been reported by Scott and Gardner (1974). The occurrence of such nonspecific, i.e., false-positive, rises in P-IgA antibody readings emphasises the need to evaluate antibody test results in relation to the clinical features, especially the duration of the infection. Of the 14

Table IV. Children with clinical pertussis : analysis by percentages in each age-group of results of tests on PNAs

\begin{tabular}{|c|c|c|c|c|c|c|c|c|c|c|c|c|c|}
\hline \multirow[b]{2}{*}{ Test results } & \multicolumn{12}{|c|}{ Age ranges (years) } & \multirow{2}{*}{$\begin{array}{l}\text { Percentages } \\
\text { of total }\end{array}$} \\
\hline & $0-\frac{3}{12}$ & $\frac{3}{12} \frac{6}{12}$ & $\frac{6}{12}-1$ & $1-2$ & $2-3$ & $3-4$ & $4-5$ & $5-6$ & $6-7$ & $7-8$ & $8-9$ & $>9$ & \\
\hline IF-positive & $(46)$ & (37) & (5) & (18) & (26) & (27) & (14) & (24) & (21) & (11) & $(0)$ & (3) & (21) \\
\hline Culture-positive & 75 & 56 & 15 & 29 & 26 & 37 & 30 & 44 & 40 & 37 & 23 & 13 & 36 \\
\hline Negative with all tests & 0 & 11 & 33 & 25 & 30 & 2 & 6 & 11 & 12 & 7 & 15 & 3 & 12 \\
\hline Antibody-doubtful & 8 & 26 & 33 & 25 & 22 & 29 & 32 & 27 & 22 & 30 & 31 & 45 & 28 \\
\hline Antibody-positive & 17 & 7 & 19 & 21 & 22 & 32 & 32 & 18 & 26 & 26 & 31 & 39 & 24 \\
\hline
\end{tabular}


non-P children whose PNAs gave false-positive $P$ IgA tests, only eight were suspected of having pertussis at presentation. Only one of these had been coughing for more than 2 weeks. It follows that a positive P-IgA test during the first 2 weeks after onset warrants special care in evaluating the clinical evidence for pertussis. It needs to be admitted that a mild attack of pertussis, which one might expect to be associated with the rapid development of P-IgA antibodies, could be difficult to confirm on clinical grounds.

A comparison of the results of our ELISAs of PIgA antibodies in PNAs with those of Robertson et al. (1987) on P-IgA antibodies in sera reveals interesting similarities and differences. With essentially the same antigen and conjugate as ours in their ELISA, they found a mean OD of 0.15 for their control group of 234 blood donors and for 13 controls age-matched against 13 culture-positive patients with pertussis. This compares with 0.154 for our non-P children. The pertussis group, defined as yielding an OD exceeding 0.41 , yielded ODs with a mean of 0.78 . The OD value of 0.41 equals the mean plus three standard deviations $(0 \cdot 15+3 \times$ $0.087)$ of the control group of blood donors. The main difference between their results and ours was the standard deviation (SD) of the ODs of the control group. Their group of adult blood donors had an SD of 0.087 , close to half of the SD of 0.17 found for the ODs of our non-P children. This difference could be related to our controls being children presenting with acute respiratory infections, or to the use of Tween-casein hydrolysate in the PBS used by Robertson et al. (1987) to dilute the serum samples.

Interbatch variation in the results of the ELISAs in the absence of a suitable standard is another concern. Although a human hyperimmune serum (Cutter Laboratories, Berkeley, CA, USA) was available to us we considered that it was not suitable as a standard because, being a serum, it does not contain secretory $\operatorname{IgA}$ and because, even when used undiluted, it produced low net $O D$ readings in the upper part of our doubtful range. Our use of pooled PNAs as positive controls showed that batch variation was slight in practice.

Table II draws attention to a limitation in any antibody test - the time lag between onset of an infection and the development of specific antibodies. This table and fig. 2 both show that the time after onset at which the highest proportion of PNAs is antibody-positive exceeds 4 weeks, while the data in table III show that some children's PNAs do not become antibody-positive until after 6 weeks (cases 6 and 7) or even later (case 8). The repeat PNAs listed in table III were not sought by us. From the diagnostic point of view there is a need to repeat PNA collections on culture-negative patients who continue to show clinical features suggesting pertussis but yielded a doubtful or negative result on the P-IgA test. Among the 395 children in our study $39 \%$ came into this category. The only commercially available ELISA for pertussis antibody tests of which we are aware (LABSYSTEMS OY; Helsinki, Finland) uses serum and also has a "doubtful" category in its results, so that a repeat serum sample is recommended when such a result is obtained.

Table IV shows that negative antibody results in culture-negative children with pertussis were particularly common in the 6-month-3 year age-range, possibly owing to an immaturity of $\operatorname{IgA}$ antibody response at that age. Nagel and Poot-Scholtens (1983), using an ELISA for serum IgA antibody, found that the time after onset for most babies $<1$ year old to produce antibody was $\geq 6$ weeks, compared with around 3 weeks for children $>1$ year old. Another explanation for some negative results could be that the antibody test used is not as sensitive as it could be. The use of filamentous haemagglutinin or other protein extractable from $B$. pertussis as antigen in an ELISA, as has been reported for assay of serum antibody (Granstrom et al., 1982, Burstyn et al., 1983) may be one way of increasing both sensitivity and specificity (Onorato and Wassilak, 1987).

Another potential diagnostic difficulty with antibody tests concerns the duration of a positive result. Although IgA antibodies have a shorter half-life than IgG antibodies, case 8 in table III shows that P-IgA antibodies may be detectable as long as 17 weeks after onset. This could lead to diagnostic confusion if a child presents with another respiratory infection within a few months of the onset of pertussis. One baby, positive for antibody initially (case 9, table III), yielded a negative antibody result 26 weeks after onset, but more information is needed.

Fig. 2 illustrates the complementary nature of the three tests done on the PNAs. The results of IF examination on direct films are usually available on the day of collection and $40 \%$ of children presenting within a week of onset had positive results with this test. Unlike some workers, we found that a positive IF test was almost always followed by a positive culture (Broome et al., 1979; Gilligan and Fisher, 1984).

About seven times as many outpatients as inpatients with pertussis were tested. This is in marked contrast to the situation before the antibody test on pernasal aspirates was introduced. Then we 
received fewer PNAs for the diagnosis of pertussis from outpatients than from inpatients. Thus, in spite of the large proportion of antibody test results assigned to the doubtful range, clinicians accepted the test in practice.

In conclusion we consider that the economy of effort and reduced stress involved in using pernasal aspirates for both culture and antibody estimation justify further work to improve the specificity and sensitivity of this ELISA for pertussis-specific IgA antibodies. Even with an improved antibody test, individual differences in antibody response are likely to require careful evaluation of the clinical

\section{REFERENCES}

Baraff L J, Wilkins J, Wehrle P F 1978 The role of antibiotics, immunizations and adenoviruses in pertussis. Pediatrics 61 : 224-30.

Broome C V, Fraser D W, English W J 1979 Pertussis diagnostic methods and surveillance. In: Manclark C R, Hill J C (eds) International symposium on pertussis. U S Departments of Health, Education and Welfare, Bethesda, MD, pp 19-22.

Broomhall J, Herxheimer A 1984 Treatment of whooping cough: the facts. Archives of Disease in Childhood 59: 185-187.

Burstyn D G, Baraff L J, Peppler M S, Leake R D, St Geme J, Manclark C R 1983 Serological response to filamentous hemagglutinin and lymphocytosis-promoting toxin of Bordetella pertussis. Infection and Immunity 41 : 1150-1156.

Gilligan P H, Fisher M C 1984 Importance of culture in laboratory diagnosis of Bordetella pertussis infections. Journal of Clinical Microbiology 20: 891-893.

Goodman Y E, Wort A J, Jackson F L 1981 Enzyme-linked immunosorbent assay for detection of pertussis immunoglobulin A in nasopharyngeal secretions as an indicator of recent infection. Journal of Clinical Microbiology 13: 286292.

Granström M, Granström G, Lindfors A, Askelöf P 1982 Serologic diagnosis of whooping cough by an enzymelinked immunosorbent assay using fimbrial hemagglutinin as antigen. Journal of Infectious Diseases 146: 741-745.

Johnston I D A, Hill M, Anderson H R, Lambert H P 1985 Impact of whooping cough on patients and their families. British Medical Journal 290: 1636-1638.

Lautrop H, Lacey B W 1960 Laboratory diagnosis of whooping cough or Bordetella infections. Bulletin of the World Health Organization 23: 15-35. features in order to make a correct interpretation of the test results and a decision as to whether the antibody test should be repeated.

We are grateful to Associate Professor K. Turner and Dr G. Stewart for technical help and advice, to Dr R. Wishart of Vancouver, Canada, for observations on the clinical diagnosis, to Professor L. Landau, Dr J. Pearman, Dr B. Wild and Mr C. Richardson for reviewing drafts of the paper, to Miss E. Pole and Mrs F. Coverley for typing the manuscript, to B. Brooks of the Statistical Branch of the State Health Department for statistical advice, and to Miss J. James of the Audiovisual Production Unit, Health Department of Western Australia for the figures.

Linnemann C C 1979 Host-parasite interactions in pertussis. In : Manclark C R, Hill J C (eds) International symposium on pertussis. U S Department of Health, Education and Welfare, Bethesda, MD, pp 3-18.

Mertsola J, Ruuskanen O, Kuronen T, Viljanen M K 1983 Serologic diagnosis of pertussis: comparison of enzymelinked immunosorbent assay and bacterial agglutination. Journal of Infectious Diseases 147: 252-257.

Nagel J, Poot-Scholtens E J 1983 Serum IgA antibody to Bordetella pertussis as an indicator of infection. Journal of Medical Microbiology 16 : 417-426.

Onorato I M, Wassilak S G 1987 Laboratory diagnosis of pertussis: the state of the art. Pediatric Infectious Disease Journal 6: 145-151.

Robertson P W, Goldberg H, Jarvie B H, Smith D D, Whybin L R 1987 Bordetella pertussis infection: a cause of persistent cough in adults. Medical Journal of Australia 146: 522-525.

Robinson D A, Mandal B K, Ironside A G, Dunbar E M 1981 Whooping cough - a study of severity in hospital cases. Archives of Diseases in Childhood 56: 687-691.

Scott R, Gardner P S 1974 The local antibody response to RS virus infection in the respiratory tract. Journal of Hygiene 72: $111-120$.

Sutcliffe E M, Abbott J D 1972 Selective medium for the isolation of Bordetella pertussis and parapertussis. Journal of Clinical Pathology 25: 732-733.

Voller A, Bartlett A, Bidwell D E 1978 Enzyme immunoassays with special reference to ELISA techniques. Journal of Clinical Pathology 31 : 507-520.

Voller A, Bidwell D E, Bartlett A 1980 Enzyme-linked immunosorbent assay. In: Rose N R, Friedman $\mathrm{H}$ (eds) Manual of clinical immunology 2nd ed, American Society of Microbiology, Washington, DC, p 366. 